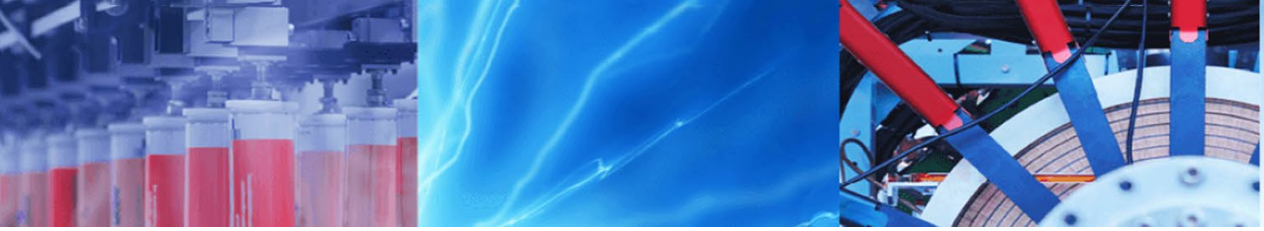

Research Article

\title{
The influence of magnetic field on the fluid flow in the entrance region of channels: analytical/numerical solution
}

\author{
Mohammad Hasan Taheri ${ }^{1}$ (D)
}

() Springer Nature Switzerland AG 2019

\begin{abstract}
The present paper investigates the steady laminar development flow of a Newtonian incompressible electrically conducting fluid in a plane channel subjected to a uniform transverse external magnetic field. In order to solve the problem, the analytical integral momentum method and numerical finite volume method (FVM) are conducted. In integral momentum solution, the Pohlhausen's fourth-degree velocity profile is assumed. Applying the boundary conditions leads to the appearance of a new dimensionless parameter named auxiliary parameter (AP). It is shown that the value of AP depends on the magnitude of magnetic intensity and the pressure gradient. For each specified value of AP, distinct velocity distribution and as a result, a correlation for computing the magnetic development length is obtained. Besides, the FVM is applied to solve the same problem and the correlation for estimating the magnetic development length is obtained. It can be concluded that for a particular engineering application of magnetohydrodynamics channel flows, the associated value of AP can be determined by the numerical investigation. The results of numerical solution are compared with the analytical results and it can be concluded that the results for $\mathrm{AP}=-6$ are in agreement with the numerical results. Further, the effect of Hartmann and Reynolds number on the magnetic development length and Lorentz force are illustrated. It was shown that as the Hartmann number increases, the value of development length and Lorentz force are reduced.
\end{abstract}

Keywords Channel · Integral momentum method · Magnetic development length · Magnetohydrodynamics . Numerical method

\section{List of symbols}

a Half width of channel $(\mathrm{m})$

AP Auxiliary parameter

$B_{0} \quad$ External magnetic field $(\mathrm{T})$

$\mathrm{Ha}$ Hartmann number

$P \quad$ Pressure $(\mathrm{Pa})$

Re Reynolds number

$u \quad x$-Component of the velocity $(\mathrm{m} / \mathrm{s})$

$U \quad$ Inlet velocity $(\mathrm{m} / \mathrm{s})$

$u_{c} \quad$ Potential core velocity $(\mathrm{m} / \mathrm{s})$

$v \quad y$-Component of the velocity $(\mathrm{m} / \mathrm{s})$

$x \quad$ Coordinate in the direction of flow $(\mathrm{m})$

$x_{\mathrm{em}} / D$ Dimensionless MHD development length

y Coordinate in the direction normal to flow $(\mathrm{m})$

$\rho \quad$ Density $\left(\mathrm{kg} / \mathrm{m}^{3}\right)$

$\begin{array}{ll}\sigma & \text { Electrical conductivity }(\Omega \mathrm{m})^{-1} \\ \delta & \text { Boundary layer thickness }(\mathrm{m}) \\ u & \text { Kinematic viscosity }\left(\mathrm{m} / \mathrm{s}^{2}\right) \\ \eta & \text { Arbitrary variable }\end{array}$

\section{Introduction}

The investigation of magnetohydrodynamics (MHD) flow in a duct or pipe is an interesting subject for researchers, e.g., electromagnetic pumps, generators and accelerators, flow-intake MHD devices, channels in reactors and some physiological uses [1-7]. The magnetic field develops the resistance Lorentz force that is dissipative in nature, so it can be used to suppress the velocity fluctuations.

Mohammad Hasan Taheri, hasan.taheri@gmail.com | 'Department of Mechanical Engineering, Sari Branch, Islamic Azad University, Sari, Iran. 
Therefore, well estimate of the channel's MHD development length has a significant role to design pertinent systems and solve practical problems in many industrial and scientific fields [8-23]. Although researches about the hydrodynamic development length and suggesting the more accurate relation for development length have been studied until now [24-28], but the attention about the magnetohydrodynamic development length and presenting the correlation for predicting it is not noticeable.

The primary studies about the effect of magnetic field on the magnetohydrodynamic development length were done by [29-37]. Maciulaitis and Loeffler [34] presented a relation for magnetohydrodynamic development length. A two-dimensional flow between two flat plates was considered and the governing equations including continuity and momentum equations were transformed to the dimensionless form and solved by the momentum integral solution. However, Hwang et al. [31, 35] studied the laminar MHD entrance flow of a plane channel and computed the MHD development length at the specified values of the Hartmann number, numerically. The results were compared [38] and showed a substantial difference.

Flores and Recuero [39] presented an analysis of an MHD channel entrance flow in the Prandtl approximation. They established the correct boundary conditions for the approximation and repeated numerical calculations carried out by Hwang et al., in a few cases. The results showed that the differences were about $10 \%$, though they increased with the augmentation of the Hartmann number.

Malekzadeh et al. [40] applied a mathematical model and a finite difference scheme to solve the governing equations of the laminar flow through a circular MHD channel. They offered an approximate mathematical expression for estimating the magnetic entrance length as a function of Hartmann number, sinus of the magnetic field angle, Reynolds number and the pipe diameter.

The focus of the mentioned researches in the field of MHD flow behavior in the entrance region in the recent years was on the pressure drop or velocity profiles variations. The development length only discussed and introduced as the length which the velocity profile does not change after that and the pressure drop becomes linear. Moreover, the correlation for the magnetohydrodynamic development length was not proposed and only the effect of flow parameters including the magnetic field, the Reynolds and Hartmann numbers on the development length has been investigated.

According to the above discussion, although a number of mathematical expressions for estimating the development length in channel flows without MHD effects have been existed in the literature $[25,27,28,41-43]$, but very little work has been done to present the closed-form correlation for predicting the MHD development length in MHD channel flows.

Indeed, in the previously published work of the authors' [44], the Newtonian and power-law non-Newtonian MHD channel flow in the entrance region was investigated. An integral momentum solution was conducted to solve the governing equations. The velocity profile was approximated as sinusoidal, and analytical correlations for the development length were obtained for both Newtonian and power-law non-Newtonian MHD flows. Besides, the effect of the Hartmann number, Reynolds number, powerlaw index and magnetic interaction parameter on the MHD development length was discussed.

As it is obvious, in integral momentum solution, applying higher-degree approximation of the velocity profile leads to the more appropriate estimate of the flow characteristics including the development length. Thus, the purpose of this paper is to increase the accuracy of the authors' previously proposed solution to MHD entrance flow of Newtonian electrically conducting fluids. The Pohlhausen's fourth-degree velocity profile is applied to approximate the velocity profile, and the correlation for the development length of the MHD channel flow is obtained. Besides, the numerical finite volume method is conducted to solve the same problem. The correlation for estimating the development length is obtained numerically, and the results of the two methods are compared with each other.

\section{Problem statement}

The geometric configuration of the MHD plane channel is shown in Fig. 1. A laminar, incompressible and Newtonian conducting fluid flow enters a rectangular channel with a uniform inlet velocity profile and developing. The fluid properties are assumed constant, and a uniform magnetic field $\left(B_{0}\right)$ is applied in the direction normal to the flow. The channel is assumed to have a sufficiently high aspect ratio for the problem to be considered two-dimensional.

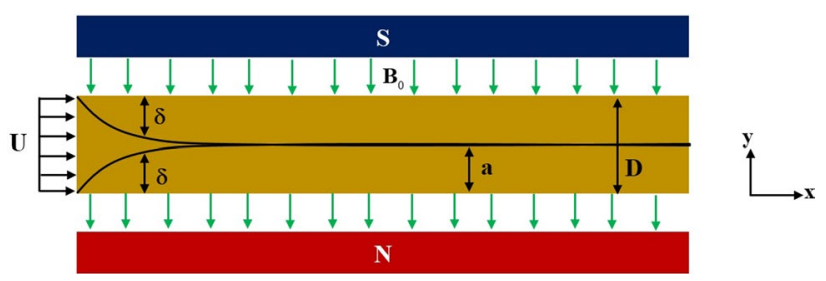

Fig. 1 Schematic of the problem 


\subsection{Governing equations for analytical method momentum integral}

For analytical solution, according to the boundary layer approximations, the governing equations including continuity and momentum are defined as [44-46]:

$\frac{\partial u}{\partial x}+\frac{\partial v}{\partial y}=0$

$u \frac{\partial u}{\partial x}+v \frac{\partial v}{\partial y}=-\frac{1}{\rho} \frac{\partial P}{\partial x}+v \frac{\partial^{2} u}{\partial y^{2}}-\frac{\sigma B_{0}^{2} u}{\rho}$

where $\rho$ is the density, $B_{0}$ is the applied magnetic field, $P$ is the pressure, $v$ is the kinematic viscosity, $\sigma$ is electrical conductivity, and $u$ and $v$ are the components of the velocity along and normal to the flow direction, respectively. In this study, the electrical field is neglected and the magnetic Reynolds number is assumed small enough. Also, the last term on the right-hand side of Eq. (1 b) is the Lorentz body force.

As in the potential core, the viscous term vanishes, also $v$ equals to zero, according to Eq. (1b), the pressure gradient can be related to the core velocity as [44]:

$\rho\left(u \frac{\partial v}{\partial x}+v \frac{\partial v}{\partial y}\right)=-\frac{\partial P}{\partial y}+\mu\left(\frac{\partial^{2} v}{\partial x^{2}}+\frac{\partial^{2} v}{\partial y^{2}}\right)$

where $\mu$ is the dynamic viscosity.

\subsection{Boundary conditions}

The boundary conditions of the problem are defined as follows:

at: $x=0: u=U$,

$y=0: \quad u=0$,

$y=\delta$ or $a: \quad u=u_{c}, \frac{\partial u}{\partial y}=0, \quad \frac{\partial^{2} u}{\partial y^{2}}=0$,

whereas $U$ is the uniform inlet velocity, $\delta$ is the boundary layer thickness, $a$ is the half width of the channel, and $u_{c}$ is the core velocity.

\section{Integral momentum solution}

the integral form of the momentum equation including the magnetic term (Lorentz body force) can be written as [44]:

$$
\frac{\mathrm{d} u_{\mathrm{c}}^{2}}{\mathrm{~d} x} \int_{0}^{\delta}\left[\left(1-\frac{u}{u_{\mathrm{c}}}\right) \frac{u}{u_{\mathrm{c}}}\right] \mathrm{d} y+\frac{\mathrm{d} u_{\mathrm{c}}}{\mathrm{d} x} u_{\mathrm{c}} \int_{0}^{\delta}\left[\left(1-\frac{u}{u_{\mathrm{c}}}\right)\right] \mathrm{d} y=v\left(\frac{\mathrm{d} u}{\mathrm{~d} y}\right)_{y=0}+\frac{\sigma B_{0}^{2} u_{\mathrm{c}}}{\rho} \int_{0}^{\delta}\left[\left(1-\frac{u}{u_{\mathrm{c}}}\right)\right] \mathrm{d} y .
$$

$u_{\mathrm{c}} \frac{\mathrm{d} u_{1 b}}{\mathrm{~d} x}=-\frac{1}{\rho} \frac{\partial P}{\partial x}-\frac{\sigma B_{0}^{2}}{\rho} u_{\mathrm{c}}$.

This equation can be named as the modified Euler equation. [44]:

Rearranging Eq. (2) and substituting to Eq. (1b), yields

$u \frac{\partial u}{\partial x}+v \frac{\partial u}{\partial y}=u_{c} \frac{\mathrm{d} u_{c}}{\mathrm{~d} x}+v \frac{\partial^{2} u}{\partial y^{2}}+\frac{\sigma B_{0}^{2}}{\rho}\left(u_{c}-u\right)$,

\subsection{Governing equations for numerical solution}

As well as analytical solution, the governing equations in numerical solutions are included the continuity and momentum which the continuity equation is as same [i.e., Eq. (1a)]. The momentum equations are introduced as $[45,46]$ :

$\rho\left(u \frac{\partial u}{\partial x}+v \frac{\partial u}{\partial y}\right)=-\frac{\partial P}{\partial x}+\mu\left(\frac{\partial^{2} u}{\partial x^{2}}+\frac{\partial^{2} u}{\partial y^{2}}\right)-\sigma B_{0}^{2} u$,
In addition, the integral form of the mass conservation can be expressed as follows:

$\int_{0}^{\delta}(\rho u) d y+\int_{\delta}^{a}\left(\rho u_{c}\right) d y=\rho U a$,

\subsection{Velocity profile approximation}

Applying Pohlhausen's fourth-degree velocity profile, the velocity profile is defined as follows:

$\frac{u}{u_{c}}=f(\eta)=\sum_{k=0}^{4} c_{k} \eta^{k}=c_{0}+c_{1} \eta+c_{2} \eta^{2}+c_{3} \eta^{3}+c_{4} \eta^{4}, \quad \eta=\frac{y}{\delta}$

As it is obvious, five boundary conditions are needed to obtain the values of the five unknown coefficients (i.e., $c_{0}$, $c_{1}, c_{2}, c_{3}$ and $c_{4}$ ) in Eq. (8). According to Eq. (5), four appropriate boundary conditions are available.

Applying the boundary condition (5b) in Eq. (1b) gives 
$u_{\mathrm{c}} \frac{\partial u_{\mathrm{c}}}{\partial x}+v \frac{\partial^{2} u}{\partial y^{2}}+\frac{\sigma B_{0}^{2}}{\rho} u_{\mathrm{c}}=0$

By some simple manipulation, we have

$\frac{\partial^{2} u}{\partial y^{2}}=-\frac{u_{c}}{v}\left(\frac{\partial u_{c}}{\partial x}+\frac{\sigma B_{0}^{2}}{\rho}\right) \quad($ for $y=0)$

Therefore, the boundary conditions (5) can be rewritten as:

$y=0: \quad u=0, \frac{\partial^{2} u}{\partial y^{2}}=-\frac{u_{c}}{v}\left(\frac{\partial u_{c}}{\partial x}+\frac{\sigma B_{0}^{2}}{\rho}\right)$

$y=\delta: \quad u=u_{c^{\prime}} \frac{\partial u}{\partial y}=0, \frac{\partial^{2} u}{\partial y^{2}}=0$

Introducing a new dimensionless parameter named Auxiliary Parameter (AP), we have

$\mathrm{AP}=\frac{\delta^{2}}{v}\left(\frac{\partial u_{\mathrm{c}}}{\partial x}+\frac{\sigma B_{0}^{2}}{\rho}\right)$

Regarding the above equation, the different values of AP can lead to the different velocity distributions and according to Eq. (12), the value of AP depends on the magnitude of the magnetic field intensity and the core velocity gradient and consequently it depends on the magnitude of the pressure gradient [see Eq. (2)].

As well, the boundary conditions can be rewritten in dimensionless form as:

$\eta=0: \quad f=0, \quad f^{\prime \prime}=-\mathrm{AP}$

$\eta=1: f=1, \quad f^{\prime}=0, \quad f^{\prime \prime}=0$

By substituting these boundary conditions (13) in Eq. (8), the velocity profile is obtained as:

$f(\eta)=\frac{u}{u_{c}}=\left(2+\frac{A P}{6}\right) \eta-\left(\frac{A P}{2}\right) \eta^{2}+\left(\frac{A P}{2}-2\right) \eta^{3}+\left(1-\frac{A P}{6}\right) \eta^{4}$

In order to obtain the theoretical range of $A P$, the following procedure is applied;
- By using boundary condition $f^{\prime}(1)=0$, we have

$$
\begin{aligned}
& \left(2+\frac{\mathrm{AP}}{6}\right)-(\mathrm{AP}) \eta+3\left(\frac{\mathrm{AP}}{2}-2\right) \eta^{2}+4\left(1-\frac{\mathrm{AP}}{6}\right) \eta^{3}=0 \\
& 2-6 \eta^{2}+4 \eta^{3}+\frac{\mathrm{AP}}{6}(1-\eta)^{3}-\frac{\mathrm{AP}}{2} \eta(1-\eta)^{2}=0 \\
& {\left[\frac{2-6 \eta^{2}+4 \eta^{3}}{(1-\eta)^{2}}\right]+\frac{\mathrm{AP}}{6}(1-\eta)-\frac{\mathrm{AP}}{2} \eta=0} \\
& {\left[\frac{2-6 \eta^{2}+4 \eta^{3}}{(1-\eta)^{2}}\right]+\frac{A P}{6}(1-4 \eta)=0} \\
& 2+4 \eta+\frac{\mathrm{AP}}{6}(1-4 \eta)=0 \\
& \eta=1 \rightarrow \mathrm{AP}=12
\end{aligned}
$$

- And using boundary condition $f^{\prime \prime}(0)=-$ AP yields

$$
4-\frac{4 A P}{6}=-A P \rightarrow A P=-12
$$

Therefore, the theoretical range of AP is obtained as:

$-12 \leq \mathrm{AP} \leq 12$

\subsection{Applying the integral momentum solution}

We continue the solution with $A P=-4$ and it is obvious, for the other value of $A P$, the solution can be obtained in the same way.

For $\mathrm{AP}=-4$, the velocity profile is obtained as:

$f(\eta)=\frac{4}{3} \eta+2 \eta^{2}-4 \eta^{3}+\frac{5}{3} \eta^{4}$.

Substituting Eq. (16) in Eq. (6) gives

$\frac{68}{567} u_{\mathrm{c}}^{2} \frac{\mathrm{d} \delta}{\mathrm{d} x}+\frac{136}{567} u_{\mathrm{c}} \delta \frac{\mathrm{d} u_{\mathrm{c}}}{\mathrm{d} x}+\frac{1}{3} u_{\mathrm{c}} \delta \frac{\mathrm{d} u_{\mathrm{c}}}{\mathrm{d} x}=\frac{4}{3} \frac{v u_{\mathrm{c}}}{\delta}+\frac{1}{3} \frac{\sigma B_{0}^{2}}{\rho} u_{\mathrm{c}} \delta$.

Equation (17) can be simplified as:

$\frac{325}{756 v} \delta^{2} \frac{\mathrm{d} u_{c}}{\mathrm{~d} x}+\frac{68}{756 v} u_{c} \delta \frac{d \delta}{d x}=1+\frac{1}{4} \frac{\sigma B_{0}^{2}}{\rho} \delta^{2}$

On the other hand, substituting Eq. (16) in Eq. (7) yields

$\frac{\delta}{D / 2}=3\left(1-\frac{U}{u_{\mathrm{c}}}\right) \rightarrow \delta=\frac{3 D}{2} \pi\left(1-\frac{U}{u_{\mathrm{c}}}\right)$

Combining Eqs. (19) and (18) gives 
Table 1 Velocity profiles and MHD development length correlations for different values of AP

\begin{tabular}{llc}
\hline$f(\eta)=\left(2+\frac{A P}{6}\right) \eta-\left(\frac{A P}{2}\right) \eta^{2}+\left(\frac{A P}{2}-2\right) \eta^{3}+\left(1-\frac{A P}{6}\right) \eta^{4}$ \\
\hline AP & $f(\eta)$ & $\frac{x_{\mathrm{em}} / D}{R e_{D}}$ \\
\hline-12 & $-3 \eta^{4}+8 \eta^{3}-6 \eta^{2}+1$ & $\frac{0.064}{1+0.1 \mathrm{Ha}^{2}}$ \\
-10 & $\frac{8}{3} \eta^{4}-7 \eta^{3}+5 \eta^{2}+\frac{1}{3} \eta$ & $\frac{0.01798}{1+0.2875 \mathrm{Ha}^{2}}$ \\
-8 & $\frac{7}{3} \eta^{4}-6 \eta^{3}+4 \eta^{2}+\frac{2}{3} \eta$ & $\frac{0.0231}{1+0.108 \mathrm{Ha}^{2}}$ \\
-6 & $4 \eta^{4}-5 \eta^{3}+3 \eta^{2}+\eta$ & $\frac{0.052}{1+0.0875 \mathrm{Ha}^{2}}$ \\
-4 & $\frac{5}{3} \eta^{4}-4 \eta^{3}+2 \eta^{2}+\frac{4}{3} \eta$ & $\frac{0.048}{1+0.0625 \mathrm{Ha}^{2}}$ \\
-2 & $\frac{4}{3} \eta^{4}-3 \eta^{3}+\eta^{2}+\frac{5}{3} \eta$ & $\frac{0.0235}{1+0.0475 \mathrm{Ha}^{2}}$ \\
0 & $\eta^{4}-2 \eta^{3}+2 \eta$ & $\frac{0.0142}{1+0.0375 \mathrm{Ha}^{2}}$ \\
2 & $\frac{2}{3} \eta^{4}-\eta^{3}-\eta^{2}+\frac{7}{3} \eta$ & $\frac{0.0133}{1+0.0309 \mathrm{Ha}^{2}}$ \\
4 & $\frac{1}{3} \eta^{4}-2 \eta^{2}+\frac{8}{3} \eta$ & $\frac{0.0128}{1+0.025 \mathrm{Ha}^{2}}$ \\
6 & $\eta^{3}-3 \eta^{2}+3 \eta$ & $\frac{0.0103}{1+0.0208 \mathrm{Ha}^{2}}$ \\
8 & $-\frac{1}{3} \eta^{4}+2 \eta^{3}-4 \eta^{2}+\frac{10}{3} \eta$ & $\frac{0.0083}{1+0.0175 \mathrm{Ha}^{2}}$ \\
10 & $-\frac{2}{3} \eta^{4}+3 \eta^{3}-5 \eta^{2}+\frac{11}{3} \eta$ & $\frac{0.00648}{1+0.0125 \mathrm{Ha}^{2}}$ \\
12 & $-\eta^{4}+4 \eta^{3}-6 \eta^{2}+4 \eta$ & $\frac{0.0054}{1+0.0125 \mathrm{Ha}^{2}}$ \\
\hline & &
\end{tabular}

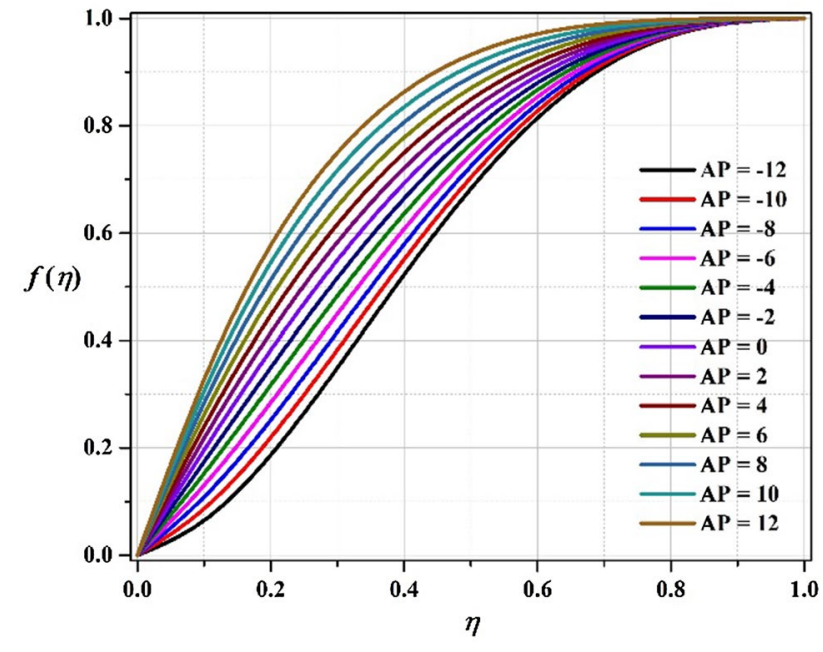

Fig. 2 Velocity profiles for different values of AP

$\frac{x / D}{R e_{D}}=\frac{\left[325 \frac{u_{c}}{u}-582 \ln \left(\frac{u_{c}}{u}\right)-257 \frac{u}{u_{c}}-68\right]}{252\left[1+\frac{9}{16} H a^{2}\left(1-\frac{u}{u_{c}}\right)^{2}\right]}$,

whereas $R e=\frac{U D}{V}$ is the Reynolds number and $H a=B_{0} \cdot D \sqrt{\frac{\sigma}{\mu}}$ is the Hartmann number.

At the end of the entrance region $\left(x_{\mathrm{em}}\right)$, each boundary layer thickness can be expressed as:

$\delta\left(x_{\mathrm{em}}\right)=\frac{D}{2}$
Table 2 Different assumed velocity profiles with the attributed MHD development length correlations

\begin{tabular}{lll}
\hline Velocity profile & $f(\eta)$ & $\frac{x_{\mathrm{em}}}{D R e_{D}}$ \\
\hline Second order & $2 \eta-\eta^{2}$ & $\frac{0.026}{1+0.0416 \mathrm{Ha}^{2}}$ \\
Third order & $\frac{3}{2} \eta-\frac{1}{2} \eta^{3}$ & $\frac{0.042}{1+0.0625 \mathrm{Ha}^{2}}$ \\
Sinusoidal [44] & $\sin \left(\frac{\pi}{2} \eta\right)$ & $\frac{0.04}{1+0.0573 \mathrm{Ha}^{2}}$ \\
\hline
\end{tabular}

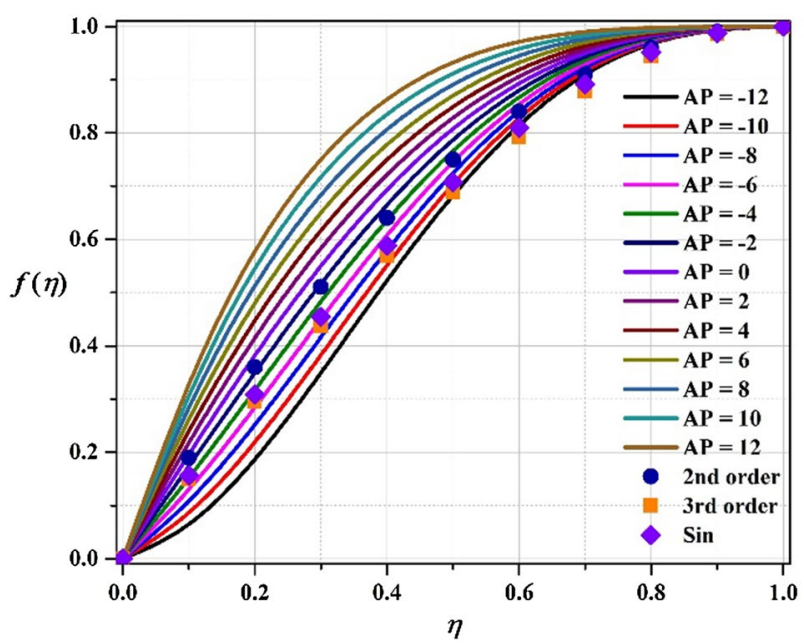

Fig. 3 Different approximations of the velocity profile

Thus, Eq. (19) reduces as:

$u_{\mathrm{c}}\left(x_{\mathrm{em}}\right)=\frac{3}{2} U$.

Indeed, the magnetic entrance length for the MHD channel flow with the assumed velocity profile is achieved by replacing Eq. (21) into Eq. (20) as:

$\frac{x_{\mathrm{em}} / D}{R e_{D}}=\frac{0.0483}{\left[1+0.0625 \mathrm{Ha}^{2}\right]}$.

\subsection{Discussion}

In this paper, the theoretical range of AP was determined and for several cases, some analytical closed-form correlations for estimating the magnetic development length were proposed. Table 1 presents the velocity distributions and the magnetic development length correlations for different values of AP. In addition, the velocity profiles $f(\eta)$ for different values of AP are shown in Fig. 2.

Table 2 and Fig. 3 are presented to compare the obtained results with the ones attributed to the lowerdegree approximations of the velocity profile. It can be seen that for the negative values of $A P$, the associated results are in better agreement with the ones of the 
Table 3 Comparison between some available results of entrance length from the literature and the present study

\begin{tabular}{lll}
\hline & $x_{\mathrm{em}} / D \mathrm{Re}_{\mathrm{D}}$ & \\
\cline { 2 - 3 } & $\mathrm{Ha=0}$ & $\mathrm{Ha}=4$ \\
\hline Present study (AP $=-12)$ & 0.064 & 0.0246 \\
Present study (AP $=-8)$ & 0.0231 & 0.0084 \\
Present study (AP $=-4)$ & 0.048 & 0.024 \\
Present study (AP=0) & 0.0142 & 0.00887 \\
Present study (AP=4) & 0.0128 & 0.00914 \\
Present study (AP=8) & 0.0083 & 0.00648 \\
Present study (AP =12) & 0.0054 & 0.0045 \\
Present study (second order) & 0.026 & 0.0156 \\
Present study (third order) & 0.042 & 0.021 \\
Taheri et al. [44] (sinusoidal) & 0.04 & 0.0208 \\
Schlichting [47] & 0.04 & - \\
Hwang et al. [35] & 0.0422 & 0.0188 \\
Roidt and Cess [37] & 0.0454 & 0.0167 \\
Bodoia and Osterle [48] & 0.044 & - \\
\hline
\end{tabular}

second order, third order and sinusoidal assumed velocity profile, than the positive values of AP. Moreover, the results of the third order and sinusoidal velocity distributions are close together and in good agreement with the results of the fourth order velocity profiles with AP between -4 and -6 . In addition, the results of the second order velocity distribution are matched with the results of the fourth order velocity distribution with $A P=-2$.

Some results for the magnetic development length obtained from the present work, the authors' previous study and the other similar works have been done so far, are shown in Table 3. With the comparison between these available results from the literature and the present study, a substantial difference among some of them can be seen. That is because of the different assumed velocity profiles or different methods which were used to solve the problem.

In light of the above discussion and for the applicable uses, in Fig. 4, the variation of the non-dimensional magnetic development length versus $\mathrm{Ha}$, for the different assumed velocity profiles associated with the different values of AP, is depicted for $R e=500,1000,1500$ and 2000. It can be observed that the results of the third order and sinusoidal velocity profiles are almost matched with each other and very close to the results of the fourth order velocity profile with $\mathrm{AP}=-4$ and -12 , especially for $\mathrm{Ha}>6$. Furthermore, for a specified value of $R e$, with the increment of $H a$, the value of the magnetic entrance length for all values of $A P$, reach to a specified value.

Figure 5 represents the variation of the non-dimensional magnetic development length versus $R e$, for the different assumed velocity profiles associated with the different values of AP, for $\mathrm{Ha}=0,4,8$ and 12. As can be seen, the results for the fourth order velocity profile with $\mathrm{AP}=-4$ and -12 are close together and are in good agreement with the values of the MHD development length for the third order and sinusoidal velocity profiles. Indeed, in general for low Hartmann numbers, applying the fourth order velocity profile with $\mathrm{AP}=-4$, and for high Hartmann numbers, employing the fourth order velocity profile with $\mathrm{AP}=-12$ led to the more accurate estimation of the magnetic development length. It can be expected that the results for AP value between -4 and -8 have more compatibility with the results of the real application. But for more assurance, further investigations are required.

The effect of $\mathrm{Ha}$ on the magnetic development length is plotted in Fig. 6. It is indicated as the $\mathrm{Ha}$ increases, the magnetic development length reduces. $\mathrm{Ha}$ is defined as the ratio of the Lorentz force to viscous force. Besides, Lorentz force is the resistance force and also proportional to the magnetic field intensity. Thus, when Lorentz force increases, the boundary layer thickness increases, and therefore, the magnetic development length decreases.

\section{Numerical solution}

This paper presents a numerical solution in order to obtain a correlation of the magnetic development length for a two-dimensional MHD channel. The numerical simulation is performed to study the liquid metal developing flow through the MHD channel for different values of the Reynolds and the Hartmann numbers using finite volume method (FVM). The investigation is conducted with laminar flows for the Reynolds number ranging from 600 to 1200 while the Hartman number varied from 4 to 14 , and 120 datasets of the magnetic development length $\left(x_{\mathrm{em}}\right)$ are generated. Liquid lithium (Li) is selected for study due to its important uses in various industries [49-51]. The hybrid scheme and central differencing are used for the convective and diffusive terms, respectively. In addition, the SIMPLE scheme is selected for pressure-velocity coupling. The algorithm was originally put forward by Patankar and Spalding [52] and is essentially a guess-and-correct procedure for the calculation of pressure on the staggered grid. In additions, the momentum and continuity equations are solved using the Jacobi iterative method. Moreover, to obtain converged results, the residual error is selected $10^{-8}$. For all calculation, the uniform and rectangular mesh grid are considered in both directions $x$ - and $y$-direction. In order to achieve valid results, the independence of the results from the mesh is checked. In Table 4, the mesh independent result is shown. It is observed that there is no variation in the results for $100 \times 80$ grid. 

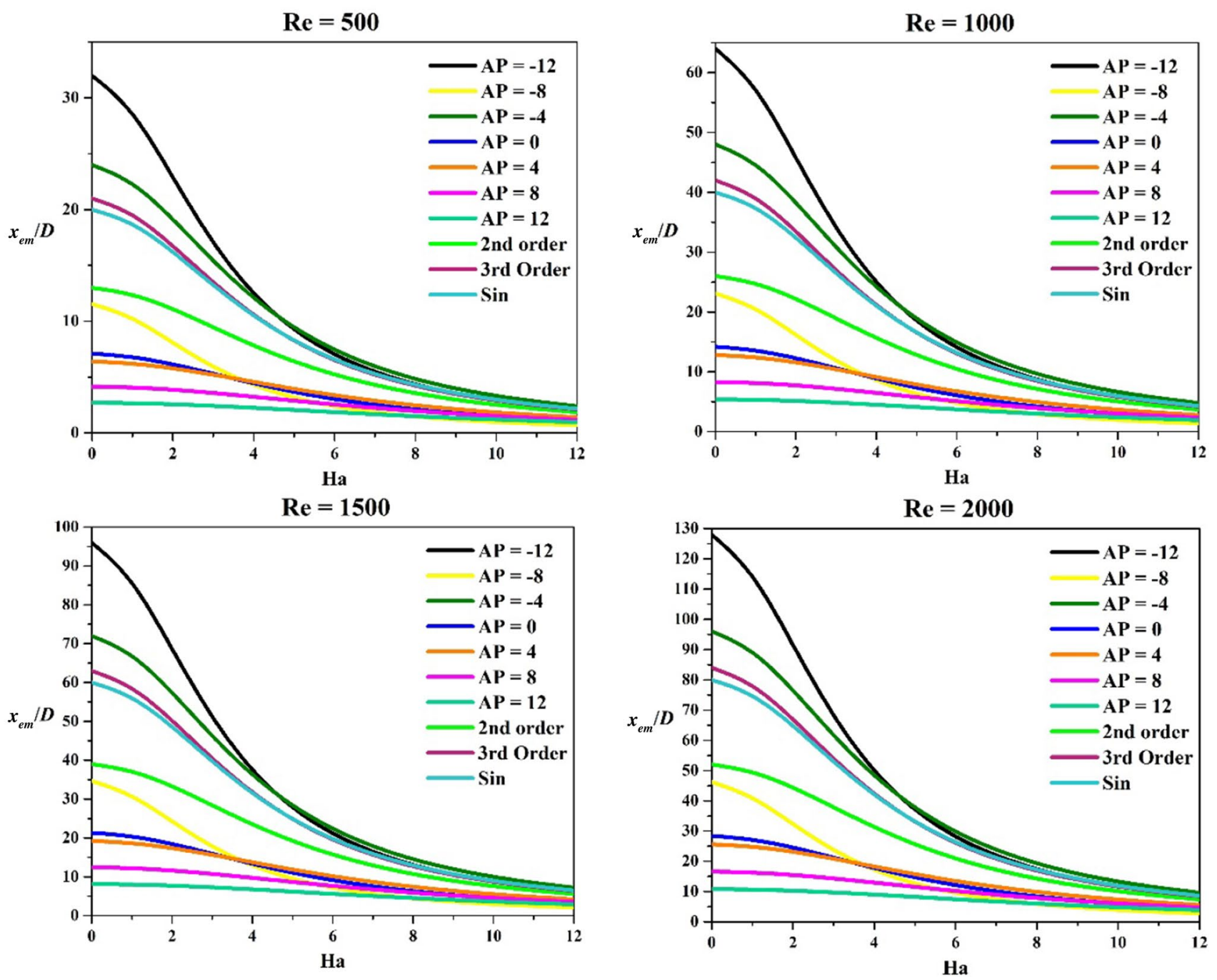

Fig. 4 Variation of $x_{\mathrm{em}} / D$ versus $\mathrm{Ha}$ for the different values of AP

Eventually, applying a surface fitted on the datasets, the correlation of the magnetic development length as a function of the Reynolds and Hartmann number is obtained as:

$\frac{x_{\mathrm{em}}}{D \operatorname{Re}_{D}}=\frac{0.057}{1+0.1 \mathrm{Ha}}$

\subsection{Discussion}

To validate the proposed correlations, Table 5 is presented. It can be observed that the proposed correlations have an acceptable accuracy.

The effect of Re and $\mathrm{Ha}$ on the development length of flow with the uniform inlet velocity is depicted in Fig. 7. It can be observed that with increasing of $\mathrm{Ha}$ and decreasing of $R e$, the development length decreases. As mentioned, $\mathrm{Ha}$ is the ratio of Lorentz force to viscous force. When $\mathrm{Ha}$ increases, the resistance Lorentz force also rises which

leads to reduction in the development length. Further, as $R e$ reduces, i.e., the viscous force increases, which the boundary layers' thickness grows, and thus, the magnetic development length becomes shorter.

In order to gain insight into some of the results, the vectors of the velocity $u$ and the Lorentz force are shown in Figs. 8 and 9. The velocity vectors along the channel are given in Fig. 8a-c. As expected, the velocity vectors change in the flow direction over the entrance region, up to the region far from entry (fully developed region) that the velocity vectors have no further change in the flow direction. As well, it can be seen that as the Hartmann number increases, the velocity vectors in the same cross section of the channel become flatten.

Figure $9 \mathrm{a}-\mathrm{c}$ shows the vectors of Lorentz force along the channel. As discussed earlier, Lorentz force is proportional to the velocity directly. Thus, the variation pattern of $F_{L}$ in the flow direction is similar to the velocity. However, 

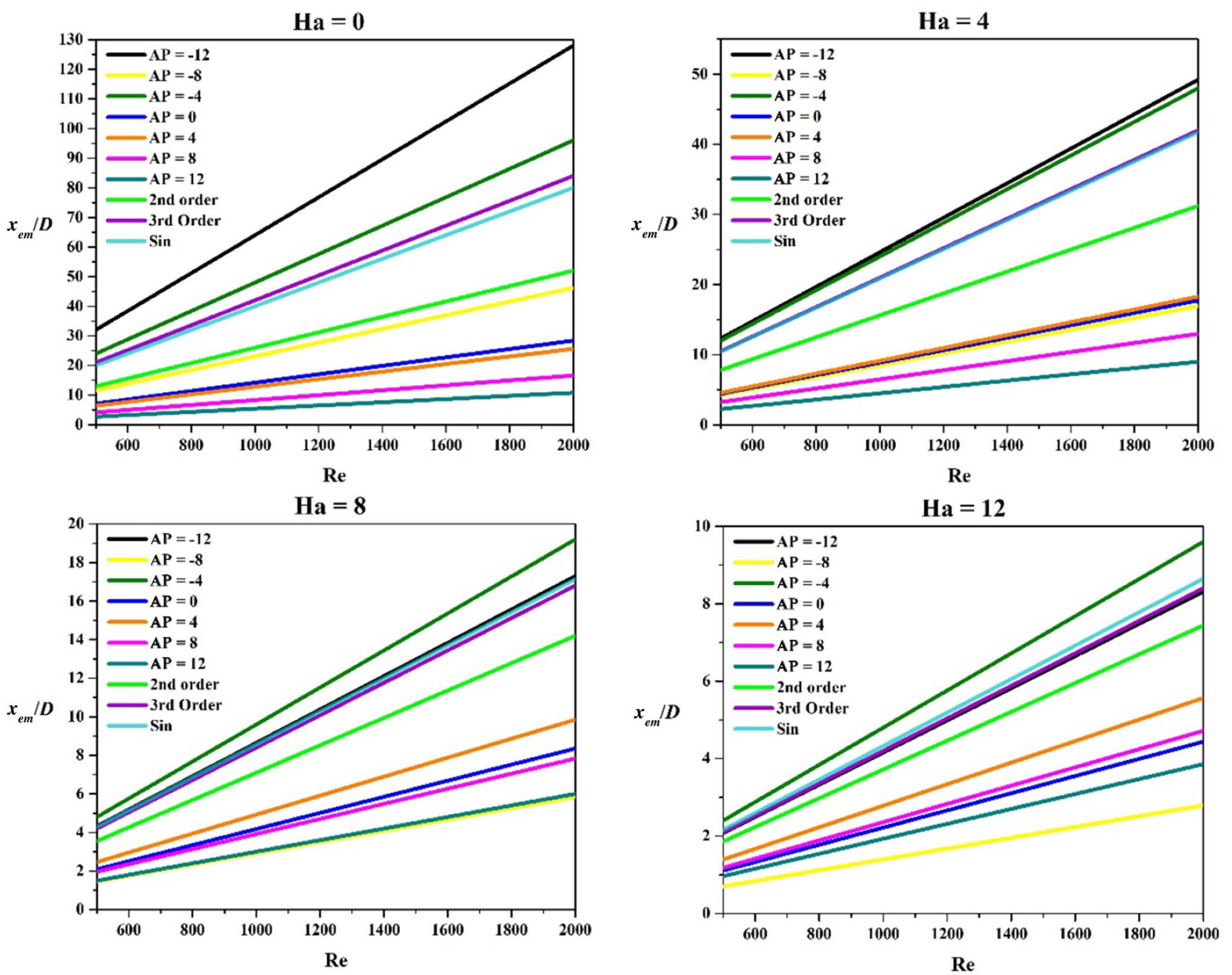

Fig. 5 Variation of $x_{\mathrm{em}} / D$ versus Re for the different values of AP

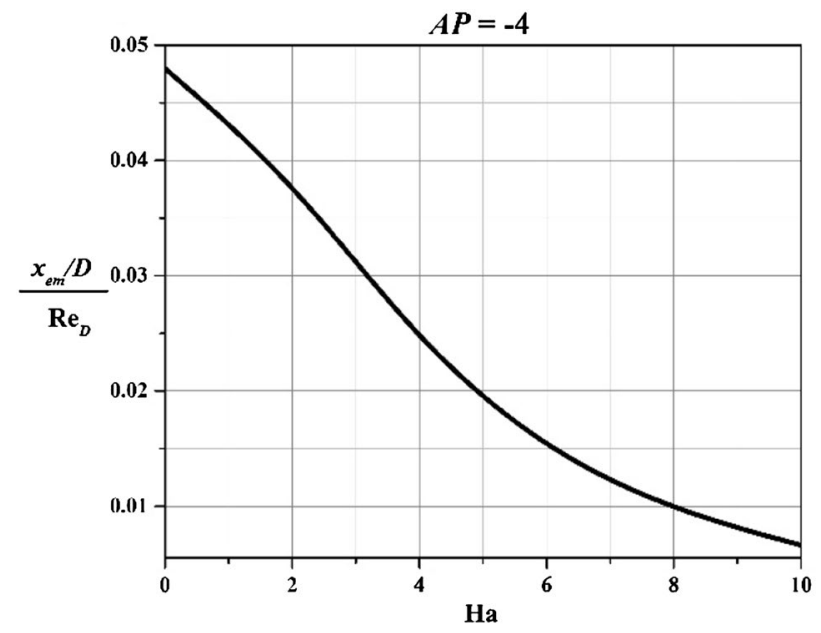

Table 4 Mesh independence for uniform inlet velocity

\begin{tabular}{llllll}
\hline$u_{\mathrm{cm}}$ & & & & & \\
\hline$R e$ & $\mathrm{Ha}$ & $50 \times 20$ & $100 \times 40$ & $100 \times 80$ & $200 \times 80$ \\
\hline 840 & 0 & 0.168 & 0.155 & 0.151 & 0.151 \\
1400 & 4 & 0.251 & 0.240 & 0.233 & 0.233 \\
\hline
\end{tabular}

Table 5 Validation of the proposed correlation

\begin{tabular}{|c|c|c|c|c|}
\hline \multirow[t]{2}{*}{$\mathrm{Ha}$} & \multicolumn{4}{|l|}{$L_{\mathrm{em}} / D R e$} \\
\hline & Equation (23) & $\begin{array}{l}\text { Recebli } \\
\text { et al. [53] }\end{array}$ & $\begin{array}{l}\text { Hwang and } \\
\text { Fan [35] }\end{array}$ & $\begin{array}{l}\text { Flores and } \\
\text { Recuero } \\
{[39]}\end{array}$ \\
\hline 0 & 0.057 & 0.05 & 0.0422 & - \\
\hline 4 & 0.0407 & - & 0.0396 & 0.0404 \\
\hline
\end{tabular}

Fig. 6 Effect of $\mathrm{Ha}$ on magnetic development length 


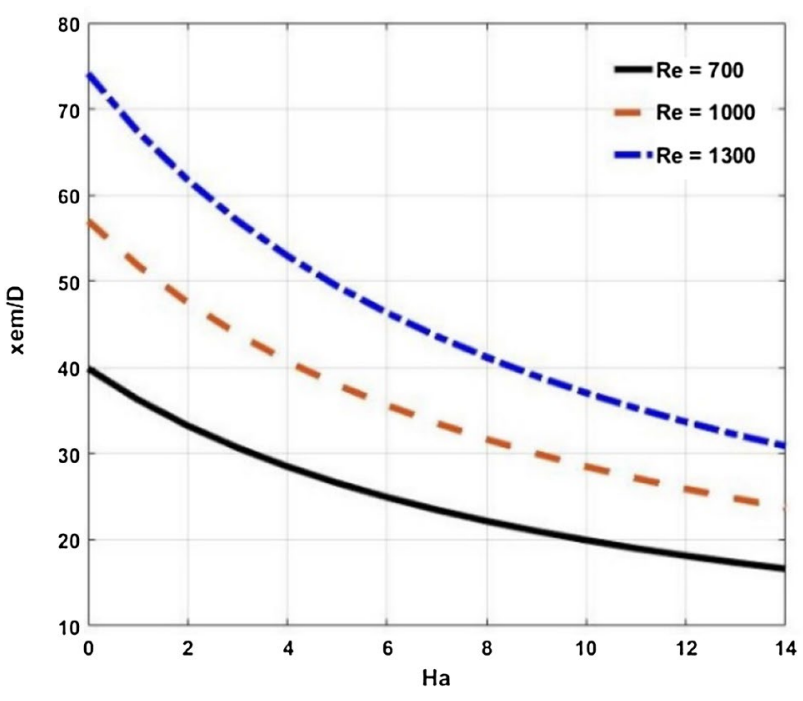

Fig. 7 Effect of $\mathrm{Ha}$ and Re on the development length

because Lorentz force is the resistance force, which affects in the opposite direction to the flow and velocity.

Eventually, in Fig. 10, the results of the analytical and numerical solution are compared. It can be seen that for $A P=-6$, the results of the analytical integral momentum solution are in good agreement with the numerical FVM.

\section{Conclusion}

In order to increase the accuracy of the authors' previously proposed non-dimensional closed-form correlation for estimating the MHD development length of MHD channel flows, the higher-degree approximation of the velocity profile was used. Applying the appropriate boundary conditions to find the values of the unknown coefficients in the Pohlhausen's fourth-degree velocity profile led to the appearance of a new dimensionless parameter named AP. It was shown that the value of AP depends on the magnitude of the magnetic field intensity and the pressure gradient. The theoretical range of AP was determined and for several cases, some analytical closed-form correlations of the MHD development length were proposed. Furthermore, the results were compared with that for the lower-degree approximations of the velocity profile and the effect of the governing parameters on the MHD development length was discussed. It can be concluded that for each particular application of MHD channel flows, the corresponding value of AP can be obtained via some experimental or numerical investigation. Indeed, the numerical finite volume method was conducted to solve the same problem and the correlation was computed numerically. Generally, by applying the Pohlhausen's fourth-degree velocity profile with $A P=-6$, more compatible results with numerical results can be obtained. Besides, the effect of the Reynolds and Hartmann number on the magnetic development length and velocity profile was discussed. It was demonstrated that with the augmentation of the $\mathrm{Ha}$,
Fig. 8 Velocity vectors along the channel $(R e=1400)$ (a) $\mathrm{Ha}=8$

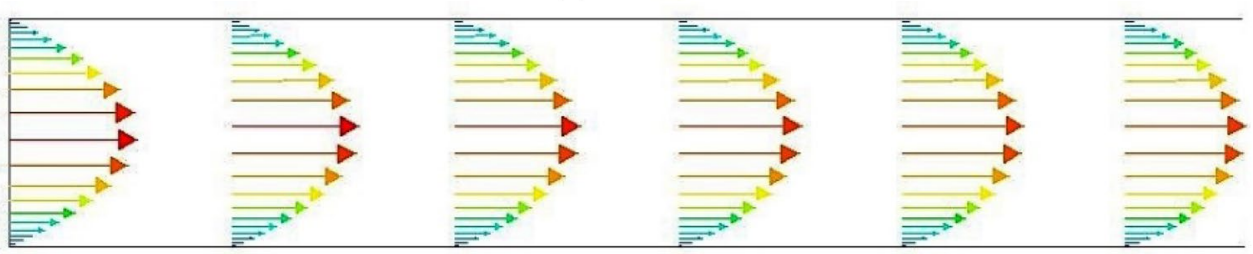

(b) $\mathrm{Ha}=12$

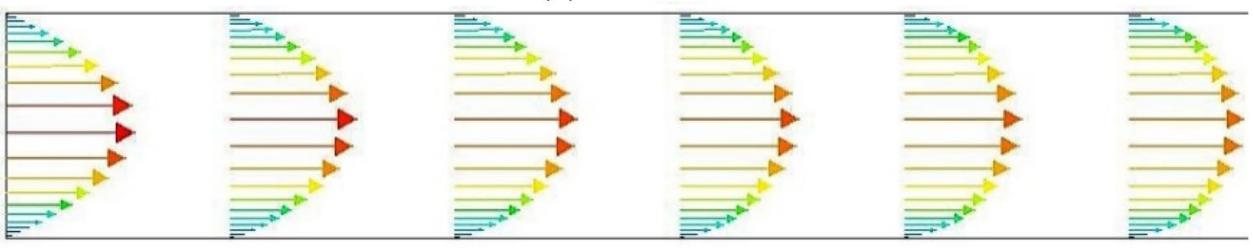

(c) $\mathrm{Ha}=16$

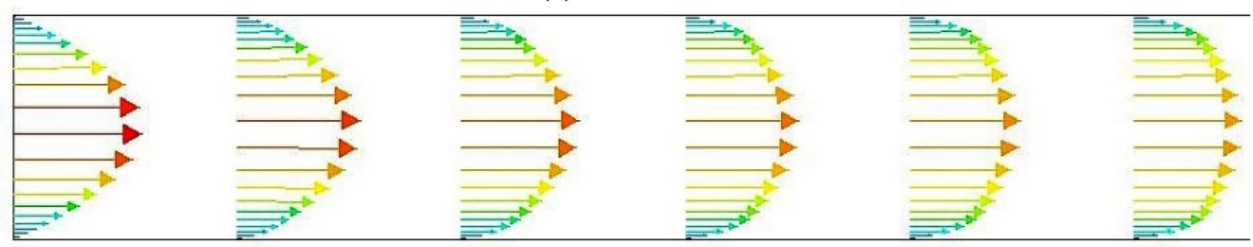

SN Applied Sciences A SPRINGER NATURE journal 
Fig. 9 Lorentz force vectors along the channel $(R e=1400)$ (a) $\mathrm{Ha}=8$

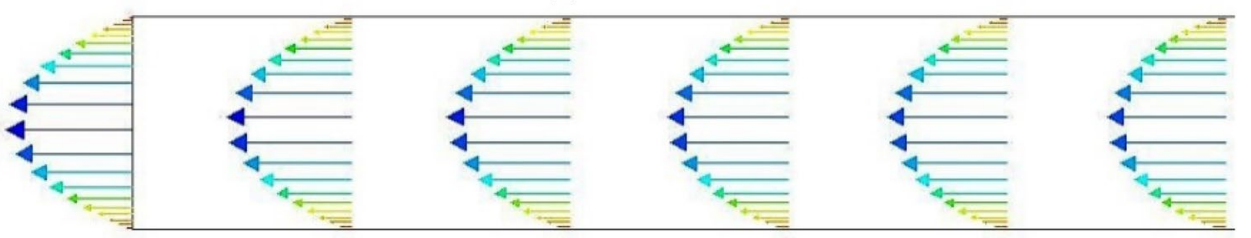

(b) $\mathrm{Ha}=12$

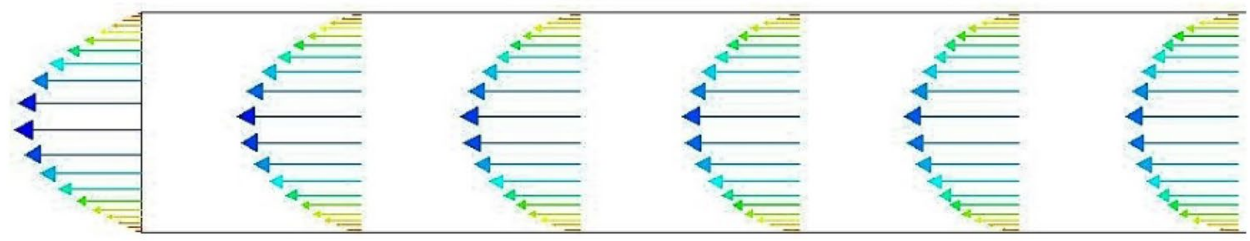

(c) $\mathrm{Ha}=16$

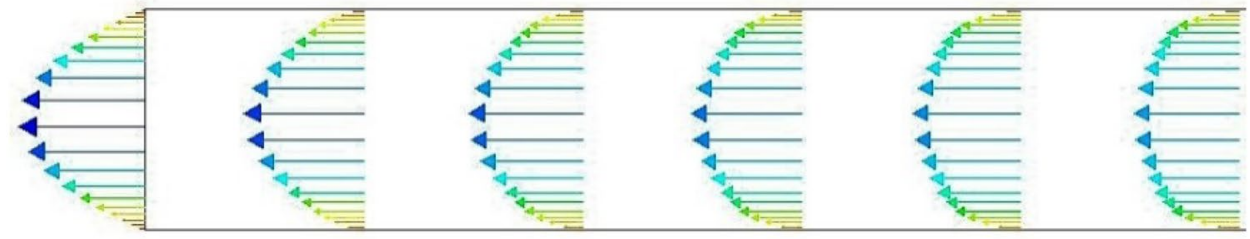

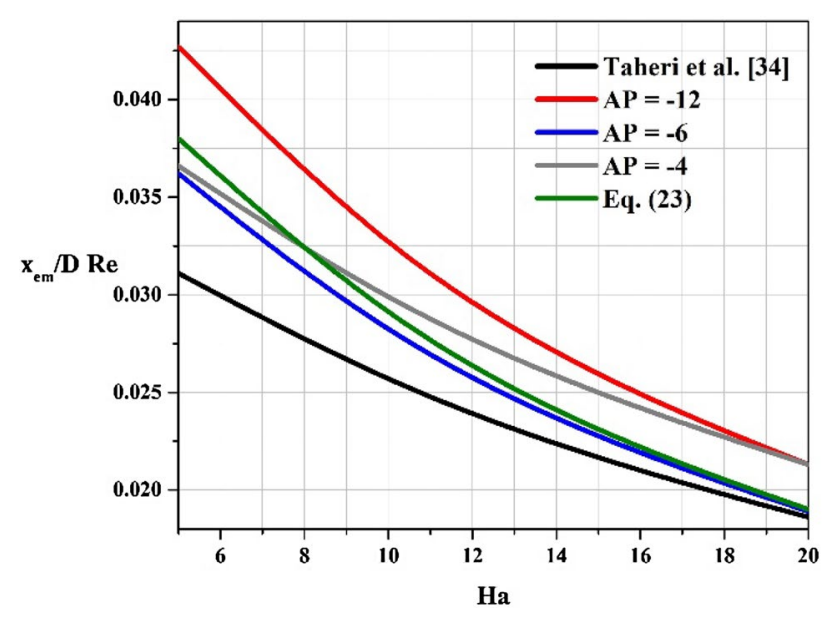

Fig. 10 Comparison of analytical and numerical results

the magnetic development length declines and the velocity profile becomes flatten. But an increase in Re leads to increase in the magnetic development length.

\section{Compliance with ethical standards}

Conflict of interest The authors declare that they have no conflict of interest.

\section{References}

1. Souayeh B, Reddy MG, Sreenivasulu P, Poornima T, Rahimi-Gorji $M$, Alarifi IM (2019) Comparative analysis on non-linear radiative heat transfer on MHD Casson nanofluid past a thin needle. J Mol Liq 284:163-174. https://doi.org/10.1016/j.molliq.2019.03.151

2. Ahmed N, Ali Shah N, Ahmad B, Shah SI, Ulhaq S, Gorji MR (2019) Transient MHD convective flow of fractional nanofluid between vertical plates. J Appl Comput Mech 5(4):592-602. https://doi. org/10.22055/jacm.2018.26947.1364

3. Okita T, Matsuda S, Yamaoka N, Hoashi E, Yokomine T, Muroga $\mathrm{T}$ (2018) Study on measurement of the flow velocity of liquid lithium jet using MHD effect for IFMIF. Fusion Eng Des. https:// doi.org/10.1016/j.fusengdes.2018.01.039

4. Javanmard M, Taheri MH, Ebrahimi SM (2018) Heat transfer of third-grade fluid flow in a pipe under an externally applied magnetic field with convection on wall. Appl Rheol 28(5):1-11

5. Hosseinzadeh K, Alizadeh M, Ganji D (2018) Hydrothermal analysis on MHD squeezing nanofluid flow in parallel plates by analytical method. Int J Mech Mater Eng 13(1):4

6. Hosseinzadeh K, Afsharpanah F, Zamani S, Gholinia M, Ganji DD (2018) A numerical investigation on ethylene glycol-titanium dioxide nanofluid convective flow over a stretching sheet in presence of heat generation/absorption. Case Stud Thermal Eng 12:228-236. https://doi.org/10.1016/j.csite.2018.04.008

7. Ghadikolaei SS, Hosseinzadeh K, Ganji DD, Jafari B (2018) Nonlinear thermal radiation effect on magneto Casson nanofluid flow with Joule heating effect over an inclined porous stretching sheet. Case Stud Thermal Eng 12:176-187. https://doi. org/10.1016/j.csite.2018.04.009

8. Rahimi-Gorji M, Pourmehran O, Gorji-Bandpy M, Ganji DD (2017) The effect of variable magnetic field on heat transfer and flow analysis of unsteady squeezing nanofluid flow between parallel plates using Galerkin method. Therm Sci 21:180. https://doi. org/10.2298/tsci160524180r

9. Hosseinzadeh K, Amiri AJ, Ardahaie SS, Ganji DD (2017) Effect of variable lorentz forces on nanofluid flow in movable parallel 
plates utilizing analytical method. Case Stud Therm Eng 10:595610. https://doi.org/10.1016/j.csite.2017.11.001

10. Ghadikolaei SS, Hosseinzadeh K, Ganji DD (2017) Analysis of unsteady MHD Eyring-Powell squeezing flow in stretching channel with considering thermal radiation and Joule heating effect using AGM. Case Stud Therm Eng 10:579-594. https://doi. org/10.1016/j.csite.2017.11.004

11. Ghadikolaei S, Hosseinzadeh K, Yassari M, Sadeghi H, Ganji D (2017) Boundary layer analysis of micropolar dusty fluid with $\mathrm{TiO} 2$ nanoparticles in a porous medium under the effect of magnetic field and thermal radiation over a stretching sheet. J Mol Liq 244:374-389

12. Smolentsev S, Courtessole C, Abdou M, Sharafat S, Sahu S, Sketchley T (2016) Numerical modeling of first experiments on PbLi MHD flows in a rectangular duct with foam-based SiC flow channel insert. Fusion Eng Des 108:7-20. https://doi. org/10.1016/j.fusengdes.2016.04.035

13. Rahimi-Gorji M, Pourmehran O, Gorji-Bandpy M, Ganji DD (2016) Unsteady squeezing nanofluid simulation and investigation of its effect on important heat transfer parameters in presence of magnetic field. J Taiwan Inst Chem Eng 67:467-475. https://doi. org/10.1016/j.jtice.2016.08.001

14. Rahimi-Gorji M, Pourmehran O, Gorji-Bandpy M, Ganji D (2016) Unsteady squeezing nanofluid simulation and investigation of its effect on important heat transfer parameters in presence of magnetic field. J Taiwan Inst Chem Eng 67:467-475

15. Pourmehran O, Rahimi-Gorji M, Ganji D (2016) Heat transfer and flow analysis of nanofluid flow induced by a stretching sheet in the presence of an external magnetic field. J Taiwan Inst Chem Eng 65:162-171

16. Moakher PG, Abbasi M, Khaki M (2016) Fully developed flow of fourth grade fluid through the channel with slip condition in the presence of a magnetic field. J Appl Fluid Mech 9(5):2239-2245

17. Courtessole C, Smolentsev S, Sketchley T, Abdou M (2016) MHD PbLi experiments in MaPLE loop at UCLA. Fusion Eng Des 109-111:1016-1021. https://doi.org/10.1016/j.fusen gdes.2016.01.032

18. Al-Habahbeh OM, Al-Saqqa M, Safi M, Abo Khater T (2016) Review of magnetohydrodynamic pump applications. Alex Eng J 55(2):1347-1358. https://doi.org/10.1016/j.aej.2016.03.001

19. Satyamurthy P, Swain PK, Tiwari V, Kirillov IR, Obukhov DM, Pertsev DA (2015) Experiments and numerical MHD analysis of LLCB TBM test-section with NaK at 1T magnetic field. Fusion Eng Des 91:44-51. https://doi.org/10.1016/j.fusengdes.2014.12.015

20. Pourmehran O, Rahimi-Gorji M, Gorji-Bandpy M, Gorji T (2015) Simulation of magnetic drug targeting through tracheobronchial airways in the presence of an external non-uniform magnetic field using Lagrangian magnetic particle tracking. J Magn Magn Mater 393:380-393

21. Patel A, Bhattacharyay R, Swain PK, Satyamurthy P, Sahu S, Rajendrakumar E, Ivanov S, Shishko A, Platacis E, Ziks A (2014) Liquid metal MHD studies with non-magnetic and ferro-magnetic structural material. Fusion Eng Des 89(7-8):1356-1361. https://doi.org/10.1016/j.fusengdes.2014.02.003

22. Lima JA, Rêgo MGO (2013) On the integral transform solution of low-magnetic MHD flow and heat transfer in the entrance region of a channel. Int J Non Linear Mech 50:25-39. https:// doi.org/10.1016/j.ijnonlinmec.2012.10.014

23. Das C, Wang G, Payne F (2013) Some practical applications of magnetohydrodynamic pumping. Sens Actuators, A 201:43-48. https://doi.org/10.1016/j.sna.2013.06.023

24. Sabau AS, Nejad AH, Klett JW, Bejan A, Ekici K (2018) Novel evaporator architecture with entrance-length crossflowpaths for supercritical Organic Rankine Cycles. Int J Heat Mass Transf 119:208-222. https://doi.org/10.1016/j.ijheatmasstrans fer.2017.11.042
25. Ma N, Duan Z, Ma H, Su L, Liang P, Ning X, He B, Zhang X (2018) Lattice Boltzmann simulation of the hydrodynamic entrance region of rectangular microchannels in the slip regime. Micromachines 9(2):87

26. Bejan A, Alalaimi M, Sabau AS, Lorente S (2017) Entrancelength dendritic plate heat exchangers. Int J Heat Mass Transf 114:1350-1356. https://doi.org/10.1016/j.ijheatmasstrans fer.2017.06.094

27. Galvis E, Yarusevych S, Culham JR (2012) Incompressible Laminar Developing Flow in Microchannels. J Fluids Eng 134(1):014503014503-014504. https://doi.org/10.1115/1.4005736

28. Sahu M, Singh P, Mahapatra SS, Khatua KK (2012) Prediction of entrance length for low Reynolds number flow in pipe using neuro-fuzzy inference system. Expert Syst Appl 39(4):45454557. https://doi.org/10.1016/j.eswa.2011.09.132

29. Wu ST, Fu TS, Wear MB (1971) Development of MHD flow in the entrance region of a channel. Rev Phys Appl 6(3):409-414

30. Schwirian RE (1970) A new momentum integral method for MHD channel entrance flows. AIAA J 8(3):565-567. https://doi. org/10.2514/3.5706

31. Hwang CL, Li KC, Fan LT (1966) Magnetohydrodynamic channel entrance flow with parabolic velocity at the entry. Phys Fluids 9(6):1134-1140. https://doi.org/10.1063/1.1761812

32. Brandt A, Gillis J (1966) Magnetohydrodynamic flow in the inlet region of a straight channel. PhysFluids 9(4):690-699. https:// doi.org/10.1063/1.1761734

33. Mffatt WC (1964) Analysis of mhd channel entrance flows using the momentum integral method. AIAA J 2(8):1495-1497. https ://doi.org/10.2514/3.2592

34. Loeffler AL, Maciulaitis A (1964) A theoretical investigation of mhd channel entrance flows. AIAA J 2(12):2100-2103. https:// doi.org/10.2514/3.2749

35. Hwang C-L, Fan L-T (1963) A finite difference analysis of laminar magneto-hydrodynamic flow in the entrance region of a flat rectangular duct. Appl Sci Res Sect B 10(3):329. https://doi. org/10.1007/bf03177939

36. Shohet JL, Osterle JF, Young FJ (1962) Velocity and temperature profiles for laminar magnetohydrodynamic flow in the entrance region of a plane channel. Phys Fluids 5(5):545-549. https://doi. org/10.1063/1.1706655

37. Roidt M, Cess RD (1962) An approximate analysis of laminar magnetohydrodynamic flow in the entrance region of a flat duct. $J$ Appl Mech 29(1):171-176. https://doi.org/10.1115/1.3636451

38. Maciulaitis A, Loeffler AL (1964) A theoretical investigation of MHD channel entrance flows. AIAA J 2(12):2100-2103. https:// doi.org/10.2514/3.2749

39. Flores F, Recuero A (1972) Magnetohydrodynamic entrance flow in a channel. Appl Sci Res 25(1):403-412. https://doi. org/10.1007/bf00382313

40. Malekzadeh A, Heydarinasab A, Dabir B (2011) Magnetic field effect on fluid flow characteristics in a pipe for laminar flow. J Mech Sci Technol 25(2):333. https://doi.org/10.1007/s1220 6-010-1223-5

41. Jasikova D, Kotek M, Kopecky V (2016) An effect of entrance length on development of velocity profile in channel of millimeter dimensions. AIP Conf Proc 1745(1):020018. https://doi. org/10.1063/1.4953712

42. Ray S, Ünsal B, Durst F (2012) Development length of sinusoidally pulsating laminar pipe flows in moderate and high Reynolds number regimes. Int J Heat Fluid Flow 37:167-176. https:// doi.org/10.1016/j.ijheatfluidflow.2012.06.001

43. Durst F, Ray S, Ünsal B, Bayoumi OA (2005) The development lengths of laminar pipe and channel flows. J Fluids Eng 127(6):1154-1160. https://doi.org/10.1115/1.2063088

44. Taheri MH, Abbasi M, Khaki Jamei M (2017) An integral method for the boundary layer of MHD non-Newtonian power-law fluid 
in the entrance region of channels. J Braz Soc Mech Sci Eng 39(10):4177-4189. https://doi.org/10.1007/s40430-017-0887-5

45. Taheri MH, Askari N, Mahdavi MH (2019) Prediction of entrance length for magnetohydrodynamics channels flow using numerical simulation and artificial neural networks. J Appl Comput Mech. https://doi.org/10.22055/jacm.2019.29201.1571

46. Taheri MH, Abbasi M, Khaki Jamei M (2019) Using artificial neural network for computing the development length of MHD channel flows. Mech Res Commun 99:8-14. https://doi.org/10.1016/j. mechrescom.2019.06.003

47. Schlichting $H(2000)$ Boundary-layer theory. 8th rev. and enl. edn. Springer, Berlin

48. Bodoia JR, Osterle JF (1961) Finite difference analysis of plane Poiseuille and Couette flow developments. Appl Sci Res 10(1):265. https://doi.org/10.1007/BF00411919

49. Lyublinski IE, Vetkov AV, Evtikhin VA (2009) Application of lithium in systems of fusion reactors. 1. Physical and chemical properties of lithium. Plasma Devices Oper 17(1):42-72. https ://doi.org/10.1080/10519990802703277

50. Duan Z, Muzychka YS (2009) Slip flow in the hydrodynamic entrance region of circular and noncircular microchannels.
J Fluids Eng 132(1):011201-011201-011213. https://doi. org/10.1115/1.4000692

51. Nygren RE, Rognlien TD, Rensink ME, Smolentsev SS, Youssef MZ, Sawan ME, Merrill BJ, Eberle C, Fogarty PJ, Nelson BE, Sze DK, Majeski R (2004) A fusion reactor design with a liquid first wall and divertor. Fusion Eng Des 72(1-3):181-221. https://doi. org/10.1016/j.fusengdes.2004.07.007

52. Patankar S (1980) Numerical heat transfer and fluid flow. McGraw-Hill, New York

53. Recebli Z, Selimli S, Gedik E (2013) Three dimensional numerical analysis of magnetic field effect on Convective heat transfer during the MHD steady state laminar flow of liquid lithium in a cylindrical pipe. Comput Fluids 88:410-417. https://doi. org/10.1016/j.compfluid.2013.09.009

Publisher's Note Springer Nature remains neutral with regard to jurisdictional claims in published maps and institutional affiliations. 